\title{
Extra-adrenal phaeochromocytoma in a resource poor setting: A case report
}

\author{
Martins Ehizode Emuze ${ }^{1}$, Arinola Esan ${ }^{1}$, Jokotade Adeleye ${ }^{1}$, Marcus O. IfeH ${ }^{2,3}$, Augustine Takure ${ }^{2}$, \\ Temilola AK ANDE ${ }^{1}$, William BALOGUN ${ }^{1}$, Abimbola Olukayode LAWAL ${ }^{1}$ \\ ${ }^{1}$ Endocrinology Unit, Department of Medicine, University College Hospital, Ibadan, Nigeria; ${ }^{2}$ Division of Urology, \\ Department of Surgery, University College Hospital, Ibadan, Nigeria; ${ }^{3}$ Department of Surgery, Federal Medical Centre, \\ Yenagoa, Bayelsa State, Nigeria \\ E-mail: ehizmart@yahoo.co.uk
}

\begin{abstract}
Phaeochromocytomas are catecholamine-secreting tumors arising in the chromaffin cells of the adrenal medulla. They are a rare cause of secondary hypertension. However, catecholamine secreting tumors may also be found in the extra-adrenal sites, producing similar symptoms as the adrenal phaeochromocytoma. The extra-adrenal phaeochromocytomas, are referred to as paragangliomas (PGLs). About 75\% of extra-adrenal phaeochromocytomas are intra-abdominal, mostly located in perinephric, periaortic, and bladder regions. Most phaeochromocytomas secrete excessive amount of epinephrine and norepinephrine, whereas most paragangliomas secrete only norepinephrine. The excessive secretion of these products could lead to paroxysms of symptoms that could be life threatening. Medical management is initially offered, but definitive treatment involves surgical removal of the tumor, which requires promptness on the both the clinician and the patient sides. We present a case of an extra-adrenal phaeochromocytoma in an adult male with revealing imaging of a mass surrounding the bladder. The patient was managed with both alpha- and beta-adrenergic blockers. He declined the surgery and eventually died after appearing in an acute hypertensive crisis.
\end{abstract}

Key words: extra-adrenal phaeochromocytoma, adrenal medulla, catecholamines, bladder

Catecholamine-secreting tumors of the adrenal medulla are known as phaeochromocytomas and when they are located outside the adrenal gland are referred to as paragangliomas (Fitzgerald 2018). Paragangliomas (PGLs) arise from the sympathetic and parasympathetic tissues, but the parasympathetic PGLs do not secrete excessive amount of catecholamines (Young 2016). In adult patients suffering from hypertension, the prevalence of phaeochromocytoma/paraganglioma (PPGL) is between $0.2-0.6 \%$ and about $5 \%$ of incidentally discovered adrenal masses has been considered to be phaeochromocytomas (Fitzgerald 2018). About $85 \%$ of pheochromocytomas arise from the adrenal medulla and about $15 \%$ from the extra-adrenal chromaffin cells (Afuwape et al. 2009; Fitzgerald 2018; Zorgani et al. 2018).
Adrenal phaeochromocytomas account for $90 \%$ of all PPGL tumors in adults. They are most common between the third and the fifth decades with equal affectation of both males and females. However, they tend to occur earlier in patients with germline mutations predisposing to PGL (Young 2016; Fitzgerald 2018; Zorgani et al. 2018). The reports regarding the PPGL are, to our knowledge, very scanty in sub-Saharan Africa. There is no report, regarding the extra-adrenal phaeochromocytoma surrounding the urinary bladder available in our region (Alema and Fualal 2010; Huddle 2011; Obarisiagbon et al. 2015; Zorgani et al. 2018).

The catecholamines secreted are epinephrine, norepinephrine, and dopamine. They are responsible for the stress response of flight or fight (Young

Corresponding author: Dr. Martins Ehizode Emuze, Endocrinology Unit, Department of Medicine, University College Hospital, PMB 5116, Queen Elizabeth Road, Oritamefa, Ibadan, Oyo State, Nigeria; phone: +2348032431790; e-mail: ehizmart@yahoo.co.uk. 
2016; Fitzgerald 2018). Epinephrine is a hormone synthesized, stored, and secreted by the adrenal gland medulla chromaffin cells. The adrenal medulla is exposed to higher concentrations of cortisol from capillaries draining adrenocortical cells, induces phenylethanolamine-N-methyltransferase (PNMT), an enzyme responsible for conversion of norepinephrine to epinephrine (Young 2016). Norepinephrine can be synthesized within the adrenal medulla and sympathetic chain outside the medulla, while dopamine, the precursor of norepinephrine, can be found in the adrenal medulla and peripheral sympathetic nerves, where it serves as a neurotransmitter (Young 2016).

Phaeochromocytoma may be benign or malignant. PGLs may present with similar symptoms as phaeochromocytomas. However, they have higher tendency to be malignant (Alema and Fualal 2010; Obarisiagbon et al. 2015; Fitzgerald 2018; Zorgani et al. 2018). They also could occur sporadically or have a genetic basis (Alema and Fualal 2010; Darr et al. 2012; Obarisiagbon et al. 2015; Fitzgerald 2018; Zorgani et al. 2018). About $75 \%$ of PGLs are intra-abdominal mostly located in perinephric, periaortic, and bladder regions (Obarisiagbon et al. 2015; Fitzgerald 2018).

PPGLs can present as episodic spells of varied symptoms including headaches, excessive sweating, palpitations, anxiety, hypertensive crisis, syncope, and tremors, and have been associated with the life-threatening complications, like myocardial infarction, renal failure, aortic dissection, arrhythmias, and stroke (Alema and Fualal 2010; Young 2016; Fitzgerald 2018; Zorgani et al. 2018). We present a case of a 32-year-old man with an abdominal extra-adrenal pheochromocytoma.

\section{Case Report}

A 32-year-old Nigerian male, who was referred to the endocrinology outpatient clinic with a 5-year history of excessive sweating, 18-month history of headaches and palpitations, which occurred intermittently and usually following micturition. The diaphoresis was said to occur spontaneously and was not related to significant exertion. There was subsequent coldness of extremities. There was no heat or cold intolerance, no anterior neck swelling, and no tremors. He complained of occasional central chest pain and had developed a sudden breathlessness about 3 weeks prior to presentation, which was managed at a peripheral hospital. There was history of dizziness, blurring of vision, and occasional nausea, but no history of differential limb weakness, and no past history of stroke. He was diagnosed with hypertension 3 years prior to the presentation. He was not known to have diabetes mellitus and there was no known family history of sudden cardiac death. He had a family history of hypertension (his mother). He was married and having one child.

General physical examination was not remarkable. The pulse was 68 beats/min, regular, normal volume; blood pressure (BP) - 140/104 $\mathrm{mmHg}$; apex beat was at the $5^{\text {th }}$ left intercostal space, lateral to the midclavicular line with heart sounds S1 and S2 only. The chest, abdominal, and neurological examinations revealed no abnormality. Based on the triad of diaphoresis, headaches, and palpitation within 5-10 minutes of micturition coupled with hypertension, a provisional diagnosis of a catecholamine secreting tumor, likely an extra-adrenal phaeochromocytoma, was made. This was substantiated by the 24 -hour urinary vanillylmandelic acid (VMA) excretion, which was elevated (Table 1). Results of serum urea, creatinine, calcium, phosphate, albumin, and lipid profile, are also listed.

Abdominopelvic ultrasound showed a huge, irregular, heterogenous mass at the base of urinary

Table 1

Results of laboratory investigations with their normal reference ranges, before and at endocrine reviews.

\begin{tabular}{|c|c|c|c|}
\hline Parameter & $\begin{array}{c}\text { Reference } \\
\text { Range }\end{array}$ & $\begin{array}{c}\text { Before } \\
\text { Presentation }\end{array}$ & $\begin{array}{c}\text { At } \\
\text { Presentation/ } \\
\text { Follow-up } \\
\text { (Endocrine } \\
\text { clinic) }\end{array}$ \\
\hline Hemoglobin (g/dl) & $14.0-18.0$ & 15.4 & \\
\hline Urea $(\mathrm{mg} / \mathrm{dl})$ & $15-45$ & 52 & 56 \\
\hline $\mathrm{Cr}(\mathrm{mg} / \mathrm{dl})$ & $0.5-1.5$ & 2.5 & 1.5 \\
\hline $\mathrm{eGFR} \mathrm{ml} / \mathrm{min} / 1.73 \mathrm{~m}^{2}$ & & 38 & 71 \\
\hline $\mathrm{Ca}^{2+}(\mathrm{mg} / \mathrm{dl})$ & $8.5-10.0$ & 10.3 & 10.8 \\
\hline $\mathrm{PO}^{3-}(\mathrm{mg} / \mathrm{dl})$ & $2.5-4.5$ & 4.0 & \\
\hline Albumin (g/dl) & $3.2-5.7$ & & 4.3 \\
\hline T-Chol (mg/dl) & $<200$ & 243 & 202 \\
\hline $\mathrm{TG}(\mathrm{mg} / \mathrm{dl})$ & $0-200$ & 156 & 516 \\
\hline HDL-C (mg/dl) & $35-86$ & 40 & 05 \\
\hline LDL-C (mg/dl) & $80-120$ & 172 & 36 \\
\hline $\begin{array}{l}\text { Urinary VMA } \\
\text { Excretion }(\mu \mathrm{mol} / 24 \mathrm{hr})\end{array}$ & $<33$ & 180.6 & \\
\hline VMA:Cr ratio & $<4.7$ & & 8.63 \\
\hline
\end{tabular}

Abbreviations: $\mathrm{Cr}$ - creatinine; eGFR - estimated Glomerular Filtration Rate; $\mathrm{Ca}^{2+}$ - calcium; $\mathrm{PO} 4^{3-}$ - phosphate; T-Chol - total cholesterol; TG - triglyceride; HDL-C - high density lipoprotein-cholesterol; LDL-C - low density lipoproteincholesterol; VMA - vanillylmandelic acid. 
bladder, difficult to separate from prostate, bilateral grade 1 renal parenchymal disease with left hydronephrosis (Figure 1). Abdominopelvic Computed Tomography (CT) scan revealed a large contrast enhanced, ill-defined isodense mass in the posteroinferior aspect of the urinary bladder with necrotic areas abutting the base of the bladder on the left and cannot be delineated from the superior part of the prostate gland and left seminal vesicle. There was a compression of the distal end of the left ureter with resultant left hydroureter and hydronephrosis with left renal hypoperfusion (Figure 2). Electrocardiogram (ECG) showed sinus tachycardia, normal axis, left ventricular hypertrophy (LVH), widespread T-wave inversion (leads I, II, aVL, V4-V6) (Figure 3). Echocardiography revealed ejection fraction (EF) $44 \%$, dilated left atrium (LA), and left ventricle (LV) with eccentric hypertrophy, grade $1 \mathrm{LV}$ diastolic dysfunction, global LV wall hypokinesia, and impaired biventricular systolic function.

Based on the clinical history and results of the investigations, he was managed as a case of extraadrenal pheochromocytoma, likely a bladder paraganglioma. Patient had medical treatment with selective $\alpha_{1}$-adrenergic blocker (doxazosin). Phenoxybenzamine, which is a nonselective $\alpha$-blocker, was not readily available. This was followed by $\beta$-adrenergic blockade with atenolol. He was placed on atorvastatin for dyslipidemia. Subsequent to the abdominopelvic ultrasound and computed tomography results, he was referred to the urologist for the definitive surgical management. Urethrocystoscopy revealed indentation of the left lateral bladder wall by the extrinsic bladder mass that appeared continuous with the prostate. Doxazosin was titrated up to $4 \mathrm{mg}$ during the period of the follow-up.

The patient was counseled for surgical removal of the tumor, but he declined on the grounds of personal and cultural belief as he reiterated that he was still young and he feared that the surgery could affect his fertility. He was educated on many occasions on the life-threatening consequences of his illness. Although the surgery was urgent, he continued in refusing it. He was admitted several times in acute pulmonary oedema over the space of 10 months and he died after presenting with another episode of sudden breathlessness, diaphoresis, and palpitations. A post-mortem was not done as relatives turned down the request.

\section{Discussion}

Phaeochromocytomas and PGLs have similar clinical presentations and are treated with similar approaches. Some clinicians use the term phaeochromocytoma to refer to both the adrenal phaeochromocytomas and the extra-adrenal catecholaminesecreting paragangliomas (Young 2016). However,

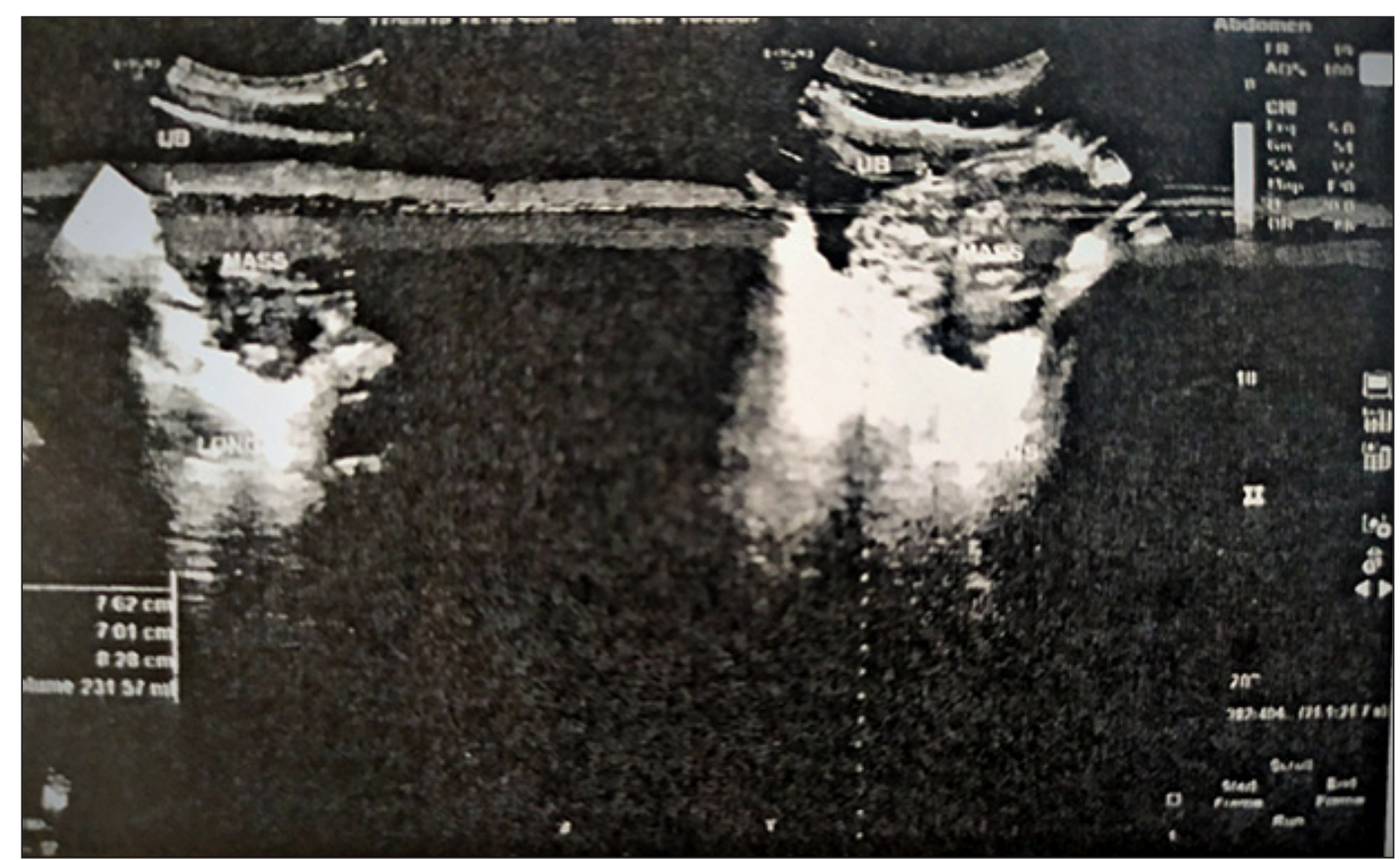

Figure 1. Abdominopelvic USS showing the mass, posterior to the urinary bladder (UB). 


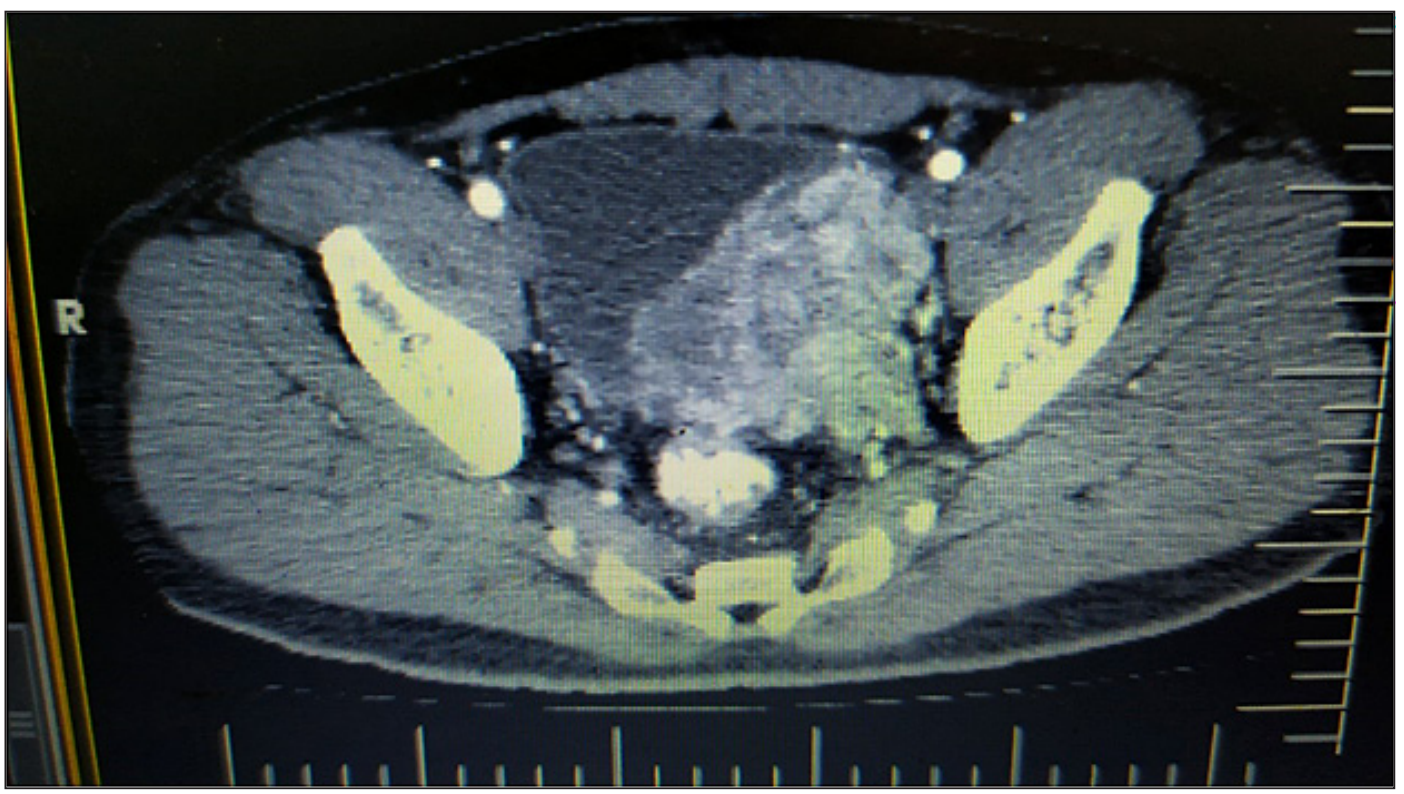

Figure 2. Abdominopelvic CT scan showing the mass with necrotic areas.

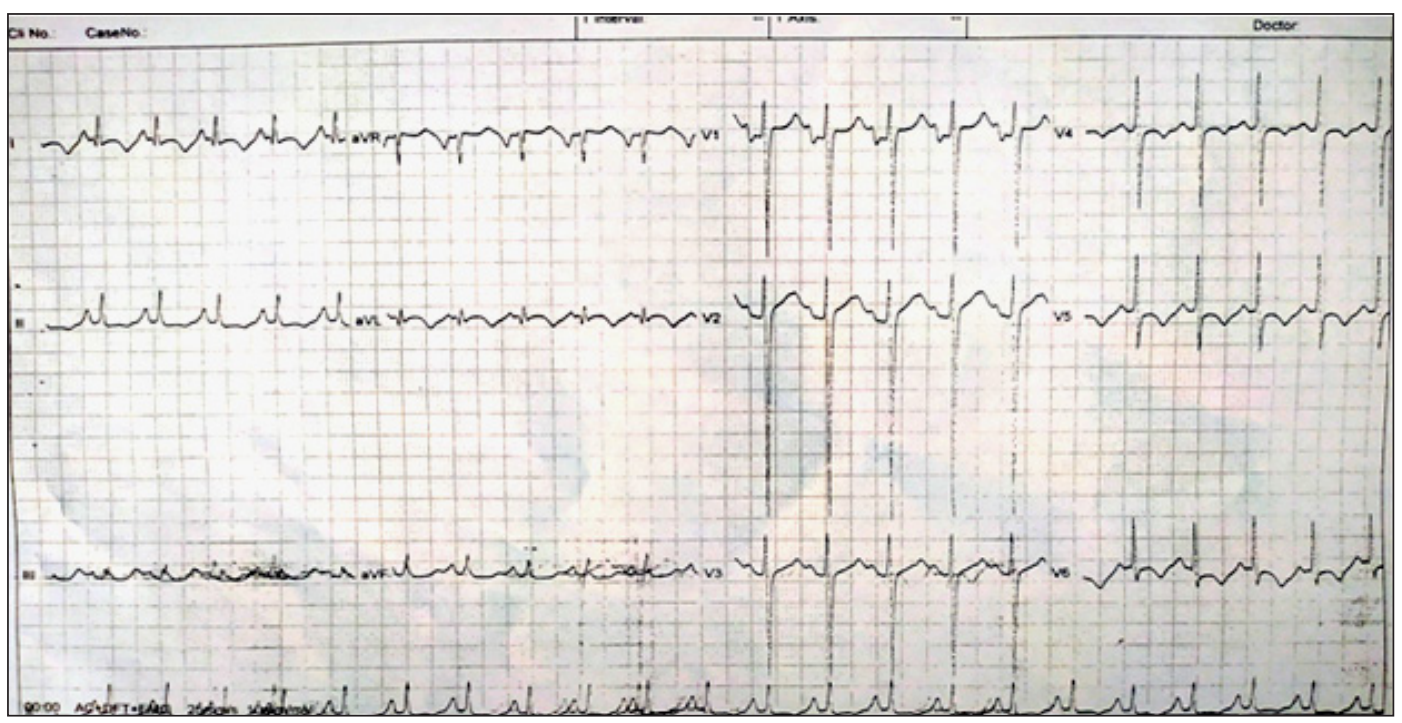

Figure 3. ECG - sinus tachycardia, normal axis, left ventricular hypertrophy (LVH), widespread T-wave inversion (leads I, II, aVL, V4-V6).

phaeochromocytomas and paragangliomas could differ in terms of implications for associated neoplasm risk for malignancy and genetic testing (Afuwape et al. 2009; Young 2016).

Most of the PGLs secrete norepinephrine and normetanephrine and $40-50 \%$ of PGLs could metastasize (Fitzgerald 2018). PPGLs could arise sporadically, but about $30-40 \%$ of patients have a germline mutation (appears higher for PGL), which predisposes to the tumor (Afuwape et al. 2009; Young 2016; Fitzgerald 2018; Zorgani et al. 2018). Genetic syndromes that have been associated with PPGL include multiple endocrine neoplasia type 2 (MEN $2 \mathrm{~A}$ and $2 \mathrm{~B}$ ), von Hippel-Lindau (VHL) syndrome, neurofibromatosis 1 (NF-1), familial paraganglioma syndromes, carney triad, and carney-stratakis syndrome, which are mostly inherited in autosomal dominant fashion and mutations in different genes 
have been noted in these syndromes (Safwat et al. 2008; Huddle 2011; Young 2016; Fitzgerald 2018; Zorgani et al. 2018).

The patients have varied symptoms because of variable tumor secretion of epinephrine and norepinephrine, but the most common symptoms of catecholamine excess, namely headache, excessive sweating, and palpitations were present in this patient. He also had the typical phaeochromocytoma triad of headache, diaphoresis, and hypertension (Safwat et al. 2008; Huddle 2011; Fitzgerald 2018; Zorgani et al. 2018). Patients with PGLs are more likely to have sustained hypertension as they secrete more norepinephrine than epinephrine (Obarisiagbon et al. 2015; Young 2016; Fitzgerald 2018). Other clinical manifestations of elaboration of catecholamines are anxiety, tremors, nausea, vomiting, epigastric/chest pain, and hyperglycemia (Young 2016; Fitzgerald 2018). These symptoms occur in paroxysms and episodes (frequency and severity increases with time) and could also occur spontaneously or after triggering by food, drugs, anesthetic/surgical procedures, mild activities like bending, exertion, abdominal palpation or micturition for bladder paraganglioma, as occurred in this patient (Huddle 2011; Young 2016; Fitzgerald 2018). PGLs could be found anywhere where the chromaffin tissue is present. About 75\% of PGLs are intra-abdominal, mostly located in perinephric, periaortic, and bladder regions (Obarisiagbon et al. 2015; Young 2016; Fitzgerald 2018).

Symptoms associated with micturition like the index patient, are suggestive of bladder paraganglioma. The symptoms occur especially after voiding large amounts of urine (Young 2016; Fitzgerald 2018). Interestingly, to our knowledge, there is no previous report available dealing with the extra-adrenal phaeochromocytoma (PGL) located to the urinary bladder in this part of the world (Alema and Fualal 2010; Huddle 2011; Obarisiagbon et al. 2015; Zorgani et al. 2018).

In addition, the patients with PPGLs often have multisystemic manifestations, as it was observed in the case of this patient. Heart failure and acute pulmonary oedema in the index patient might be a consequence of systemic hypertension. Activation of cytokines, especially interleukin 6 (IL-6), can result in an acute respiratory distress syndrome (ARDS). Cardiomyopathy could result from the left ventricular hypertrophy (present in the patient), systemic hypertension or ischemia or excess of catecholamines (Young 2016; Fitzgerald 2018). The patient presented in this case report also had renal insufficiency, which has already been reported in PGL patients. Possible etiologies of the renal failure in patients with PGL include hypertensive nephrosclerosis, invasion of renal vein/artery by the tumor, acute tubular necrosis, myoglobinuric renal failure (from rhabdomyolysis), and nephrotic syndrome from secretion of IL-6 (Young 2016; Fitzgerald 2018).

The diagnosis of the extra-adrenal phaeochromocytoma is made based on the clinical suspicion of the catecholamines excess, biochemical evidence in keeping with high levels of catecholamines and their metabolites, and tumor localization via imaging (Huddle 2011; Young 2016; Fitzgerald 2018; Zorgani et al. 2018). Over the years, plasma and urinary assays of catecholamines have been developed with different sensitivity and specificity. The metanephrines are degradation products of epinephrine and norepinephrine. Currently, the preferred tests for laboratory diagnosis include the measurement of 24-hour urinary fractionated metanephrines (with a sensitivity and specificity of 91-98\%) and plasma fractionated metanephrine assay (sensitivity of $96-100 \%$ and specificity of $85-89 \%$ ), which should be collected from patient lying in a supine position to limit false positive results (Young 2007; Darr et al. 2012; Lenders et al. 2014; Young 2016; Fitzgerald 2018; Zorgani et al. 2018).

In resource-constrained setting, urinary vanillyl mandelic assay (VMA) with a sensitivity of $90 \%$ and specificity up to $95 \%$, may be assayed (Lenders et al. 2002; Fitzgerald 2018), which was elevated in this patient. Hypercalcemia, which was present in this patient, may be an isolated finding in PPGL or may be associated with a genetic syndrome of primary hyperparathyroidism like MEN 2A, a result of an ectopic secretion of parathyroid hormone-related protein (PTHrP) by the tumor or bony metastasis. It usually resolves after tumor resection (Young 2016; Fitzgerald 2018; Angelousi et al. 2019). In the view of a possible primary hyperparathyroidism and MEN $2 \mathrm{~A}$ considering the hypercalcemia in the patient, parathyroid hormone (PTH) assay was requested, but was not done. Our patient did not have abdominal pain, bone pains, constipation, renal stones or ultrasound findings of renal medullary nephrocalcinosis, which are other features of the primary hyperparathyroidism.

Computed tomography or magnetic resonance imaging (MRI) are modalities for the tumor localization, but CT is recommended as the first choice because of its excellent spatial resolution for the thorax, abdomen, and pelvis. The mass may be homogenous or heterogeneous with solid, cystic, calcified or necrotic areas (Lenders et al. 2014; Kumar 
et al. 2015; Young 2016; Fitzgerald 2018). About 10\% of PGLs are localized to the urinary bladder and bladder paraganglioma appears as a well-defined nonpapillary, well enhancing heterogeneous lesion (Kumar et al. 2015; Young 2016).

In the cases of metastatic disease, ${ }^{123} \mathrm{I}$-metaiodobenzylguanidine ( $\left.{ }^{123} \mathrm{I}-\mathrm{MIBG}\right)$ scintigraphy and ${ }^{18} \mathrm{~F}-$ fluorodeoxyglucose positron emission tomography/ computed tomography $\left({ }^{18} \mathrm{~F}-\mathrm{FDG}\right.$ PET/CT) scanning could be employed, but ${ }^{18} \mathrm{~F}-\mathrm{FDG}$ PET/CT is the preferred imaging modality over ${ }^{123} \mathrm{I}-\mathrm{MIBG}$ scintigraphy in patients with known metastatic PGLs (Darr et al. 2012; Lenders et al. 2014; Fitzgerald 2018).

The main treatment for PGLs is a surgical resection of the tumor, but initial medical management using $\alpha$-adrenergic blockade (phenoxybenzamine, prazosin, doxazosin) is done, where phenoxybenzamine is preferred due to its nonselective irreversible blockade of $\alpha$-receptors and long duration of action. Then $\beta$-adrenergic blockers (propranolol, metoprolol, atenolol) are offered before definitive surgery (Afuwape et al. 2009; Lenders et al. 2014; Obarisiagbon et al. 2015; Young 2016; Fitzgerald 2018). Tumor debulking, metabolic radiotherapy, chemotherapy, and tyrosine kinase inhibitors could be offered for malignant/metastatic diseases (Plouin et al. 2010; Young 2016; Fitzgerald 2018; Angelousi et al. 2019).

A high index of suspicion is required as delay in the detection and management could result in life-threatening medical emergencies. The main causes of death in PPGL are cardiac arrhythmias, myocardial infarction, stroke, cardiomyopathy, ARDS or multisystem crisis (constellation of ARDS, renal failure, hepatic failure, shock, cardiomyopathy, disseminated intravascular coagulation) (Young 2016; Fitzgerald 2018).

\section{Conclusion}

The early diagnosis of the extra-adrenal phaeochromocytoma is important for a better clinical outcome. The symptoms of the patient in the case report started 5 years earlier with delay before the eventual diagnosis. Adequate investigation of young persons with hypertension, appropriate and prompt referrals of suspected cases to specialist centers is crucial.

Genetic testing should be considered for patients with the extra-adrenal phaeochromocytoma, bilateral adrenal pheochromocytoma, unilateral adrenal pheochromocytoma and a family history of pheochromocytoma/paraganglioma, unilateral adrenal pheochromocytoma with onset at a young age ( $<45$ years) or other clinical findings suggestive of one of the previously mentioned syndromic disorders (Young 2016; Lenders et al. 2014). Screening for categories of patients with PPGLs should be pursued when relevant facilities are in place, e.g., young patient with resistant hypertension, extra-adrenal phaeochromocytoma/PGLs, family history of PPGLs, and family history of MEN 2 syndrome.

\section{Acknowledgments}

Resident doctors, who were involved in the management of the patient during the different hospital admissions, are hereby acknowledged.

\section{References}

Afuwape O, Ladipo JK, Ogun O, Adeleye J, Irabor D. Pheochromocytoma in an accessory adrenal gland: a case report. Cases J 2, 6271, 2009.

Alema ON, Fualal JO. Extra-adrenal Pheochromocytoma: Experience in Mulago Hospital. East Central Afr J Surg 15, 144-149, 2010.

Angelousi A, Peppa M, Chrisoulidou A, Alexandraki K, Berthon A, Faucz FR, Kassi E, Kaltsas G. Malignant pheochromocytomas/paragangliomas and ectopic hormonal secretion: a case series and review of the literature. Cancers 11, 724, 2019.

Darr R, Lenders JW, Hofbauer LC, Naumann B, Bornstein SR, Eisenhofer G. Pheochromocytoma-update on disease management. Ther Adv Endocrinol Metab 3, 11-26, 2012.

Fitzgerald PA. Adrenal Medulla and Paraganglia. In: Greenspans Basic Clin Endocrinol 10th ed. (Eds. Gardner D, Shobach D), pp. 359-409, McGraw-Hill, China, 2018.

Huddle KR. Phaeochromocytoma in black South Africans-a 30-year audit. S Afr Med J 101, 184-188, 2011.

Kumar S, Choudhary GR, Singh S, Prasad S, Singh SK, Bhansali A, Bhadada S, Dutta P. Spectrum of retroperitoneal and genitourinary paraganglioma: Experience at a North Indian tertiary care center. Cent European J Urol 68, 421-427, 2015.

Lenders JWM, Pacak K, Walther MM, Linehan WM, Mannelli M, Friberg P, Keiser HR, Goldstein DS, Eisenhofer G. Biochemical diagnosis of pheochromocytoma: Which test is best? JAMA 287, 1427-1434, 2002. 
Lenders JW, Duh QY, Eisenhofer G, Gimenez-Roqueplo AP, Grebe SK, Murad MH, Naruse M, Pacak K, Young WF Jr; Endocrine Society. Pheochromocytoma and paraganglioma: an endocrine society clinical practice guideline. J Clin Endocrinol Metab 99, 1915-1942, 2014.

Obarisiagbon EO, Agbugui JO, Forae G. Paraganglioma: a rare retroperitoneal tumor. Arch Int Surg 5, $220,2015$.

Plouin PF, Amar L, Lepoutre C. Phaeochromocytomas and functional paragangliomas: clinical management. Best Pract Res Clin Endocrinol Metab 24, 933-941, 2010.

Safwat AS, Bissada NK, Seyam RM, Safwat AS, Bissada NK, Seyam RM, Al Sobhi S, Hanash KA. The clinical spectrum of pheochromocytoma: analysis of 115 patients. BJU Int 101, 1561-1564, 2008.

Zorgani AE, Pirie FJ, Motala AA. Characteristics and outcome of patients with pheochromocytoma at a tertiary endocrinology clinic in Durban, South Africa over 14 years. J Endocrinol Metab Diabet South Africa 23, $52-58,2018$.

Young WF Jr. Clinical practice. The incidentally discovered adrenal mass. N Engl J Med 356, 601-610, 2007.

Young WF. Endocrine Hypertension. In: Williams Textbook of Endocrinology 13th ed. (Eds. Melmed S, Polonsky K, Larsen R, Kronenberg H), pp. 559-573, Elsevier, Philadelphia, 2016. 